\title{
Enhanced Production of Shigella flexneri Polysaccharide from a Newly Devised Silicate Method as a Potential Vaccine Conjugate
}

\author{
P. V. S. L. S. S. Narayana ${ }^{1}$ Jayati Ray Dutta ${ }^{1}$
}

Received: 3 May 2019 / Revised: 27 July 2019 / Accepted: 23 September 2019 / Published online: 3 October 2019

(c) Springer Science+Business Media, LLC, part of Springer Nature 2019

\begin{abstract}
Conventional glycoconjugates are prepared with polysaccharides (PS) isolated from bacterial sources by fermentation technique. This approach has some major challenges like lower yield of PS, impurities and usage of hazardous chemicals. Reports on efficient and enhanced production of PS from Shigella flexneri is meager in literature. Hence, in the current study, three different types of media namely Yeast extract medium, Shigella sonnei-defined medium and synthetic medium were utilized for the culture of S. flexneri. Among the selected media it was recognized that the culture of S. flexneri harvested in synthetic media produced significant quantity of PS in less time when compared to the other two media. Different purification techniques such as phenol chloroform extraction, acid precipitation, detergent method, chromatographic purification and a novel silicate method were carried out to refine the harvested PS from impurities. It was observed that large impurities such as bacterial protein, debris and media components were eliminated significantly by using chromatographic and silicate methods. The final yield of purified PS was approximately 20-35\% higher in silicate method which is reported for the first time in this study for purification of PS. Further, the characterization of the purified PS was done using high-performance liquid chromatography and high-performance anion-exchange chromatography with pulsed amperometric detection. Hence, the robust process developed in the present study using synthetic media and chromatographic filtration technique along with the novel silicate treatment produced significant quantities of PS from S. flexneri in reduced cost and time, which could be further conjugated to a suitable carrier to generate a potential Shigella conjugate antigen.
\end{abstract}

\section{Introduction}

Entero-invasive gram-negative Shigella bacteria are the human pathogens that cause severe infection known as Shigellosis. The disease is estimated to affect approximately 165 million people annually, leading to 1.1 million deaths per year [1]. This shigellosis remains a major cause of diarrheal disease in the developing countries and causes substantial morbidity and mortality in children under the age of five years [2]. It is in the top four pathogens that cause moderate-to-severe diarrhea in African and South Asian children. Worldwide over 188 million cases of shigellosis occur annually and around 1, 64,000 associated deaths take place [3].

In view of these deaths and the severity caused by Shigella infections, many control measures were implemented

Jayati Ray Dutta

jayati@hyderabad.bits-pilani.ac.in

1 Department of Biological Sciences, BITS Pilani, Hyderabad Campus, Jawahar Nagar, Kapra Mandal, Hyderabad, Telangana 500078, India such as basic sanitation, usage of antibiotics and education control. But it is often difficult to control these bacterial outbreaks due to the development of multidrug-resistant Shigella strains [Lambert]. Hence, the development of a safe and effective vaccine against this Shigellosis is a prior strategy for the World Health Organization [3]. To develop a vaccine candidate against these Shigella strains, many research strategies were undertaken. Among them, from the literature, it is evident that conjugate vaccines are the most efficient and preventive approach against these bacterial infections such as caused by Haemophilus influenzae type b, Neisseria meningitidis, Salmonella typhi and Streptococcus pneumoniae [4]. All these conjugate vaccines consist of capsular polysaccharides as their main moiety along with the carrier proteins.

In Shigella species, the main surface antigen is polysaccharide (PS) and various attempts were made to chemically conjugate it with carrier proteins such as diphtheria toxoid and tetanus toxoid [5]. A better control of Shigella infections is dependent on the high immunization uptake by individuals and this disease outbreak can be prevented by developing a 
new generation of conjugated PS vaccines linked to potential carrier proteins. For this respective PS vaccine development, a very large-scale industrial production of PS from $S$. flexneri is necessary. At present, the cost of cultivation and production of PS from S. flexneri in a bioreactor is generally high and requires robust process [6]. And also very meager information is available from the literature on this process of improved production and purification of PS from S. flexneri for a pilot or industrial scale synthesis. Traditional purification processes of bacterial PS often involved hazardous solvents such as ethanol, phenol and cationic detergent

s. And experiments with enzymatic treatments did not produce required purity of bacterial PS.

Therefore, in the present study, investigations on the optimum growth rate of $S$. flexneri were done utilizing three different media, namely Yeast extract medium, Shigella sonnei-defined medium and synthetic media. Hestrin assay was performed to detect the quantity of PS in the cultures of $S$. flexneri grown from these three different media. To attain purified PS from S. flexneri, devoid of proteins and nucleic acid impurities, various purification methods were employed. Initially, traditional molecular weight cut off studies, phenol chloroform extraction, acid precipitation and detergent methods were carried out to purify the produced PS from S. flexneri cultures. Further, for more enhanced yield and efficient purification of S. flexneri PS, chromatographic purification and novel silicate methods were employed. Later, to analyze the average molecular weight distribution of the purified PS of S. flexneri, HPLC method was used. HPAEC-PAD was used to evaluate the different sugar composition of total PS of the S. flexneri. Overall, the present study is aimed to increase PS production from $S$. flexneri and to devise an efficient purification system for a potential vaccine conjugate.

\section{Materials and Methods}

\section{Bacterial Strain}

S. flexneri ATCC 120,922 (one lyophilized vial) used in the current study was procured from NCIM (National collection of Industrial microorganisms), Pune, India. Glycerol stocks of the strain was prepared and stored at $-70^{\circ} \mathrm{C}$ [7]. All the chemicals used in the present study were purchased from Merck and Sigma, India.

\section{Growth Media}

\section{Yeast Extract Medium (HTMC)}

Cultures of Shigella flexneri were inoculated into $50 \mathrm{ml}$ of yeast extract (HTMC) medium and incubated at $37^{\circ} \mathrm{C}$ at
$20 \times g$ for $30 \mathrm{~h}$. Seed cultures were developed by sub-culturing into $300 \mathrm{ml}$ of HTMC medium and incubated in a rotary shaker at $37^{\circ} \mathrm{C}$ at $17 \times g$ for $26 \mathrm{~h}$. Composition of the medium included $30 \mathrm{~g}$ of yeast extract, $5.0 \mathrm{~g}$ of $\mathrm{KH}_{2} \mathrm{PO}_{4}$, $20 \mathrm{~g}$ of $\mathrm{K}_{2} \mathrm{HPO}_{4}, 1.2 \mathrm{~g}$ of $\mathrm{MgSO}_{4} \cdot 7 \mathrm{H}_{2} \mathrm{O}, 1.5 \mathrm{ml}$ glycerol and $0.25 \mathrm{ml}$ of polypropylene glycol in a final volume of one litre distilled water. The $\mathrm{pH}$ was adjusted to $7.0 \pm 0.2$ using $0.25 \mathrm{M} \mathrm{NaOH}$. The medium was filtered through 0.2 $\mu \mathrm{m}$ gamma irradiated capsule filter and added aseptically to the cultures of $S$. flexneri. Then, culturing was performed at $37{ }^{\circ} \mathrm{C}, \mathrm{pH} 7.0$ and $35 \times g$ of agitation speed. The different agitation speeds have been used as per the report by Scorza et al. [7] to obtain the maximal growth at $600 \mathrm{~nm}$. Sterilized deoxycholate detergent of $0.5-1.0 \% \mathrm{w} / \mathrm{v}$ was added to the culture broth after attaining an optical density $\left(\mathrm{OD}_{600}\right)$ of 0.5 to extract the PS from the cell wall of S. flexneri [7].

\section{Shigella sonnei Defined Medium (SSDM)}

Seed cultures of Shigella flexneri were developed by subculturing into $300 \mathrm{ml}$ of Shigella sonnei-defined medium (SSDM) and incubated in a rotary shaker at $37^{\circ} \mathrm{C}, 17 \times g$ of agitation for $28 \mathrm{~h}$. The composition of the medium included $30 \mathrm{~g}$ of glycerol, $13.3 \mathrm{~g}$ of $\mathrm{KH}_{2} \mathrm{PO}_{4}, 20 \mathrm{~g}$ of $\left(\mathrm{NH}_{4}\right)_{2} \mathrm{HPO}_{4}$, $1.2 \mathrm{~g}$ of $\mathrm{MgSO}_{4} \cdot 7 \mathrm{H}_{2} \mathrm{O}, 1.7 \mathrm{~g}$ citric acid, $0.25 \mathrm{ml}$ of polypropylene glycol and trace elements in a final volume of 1 litre of distilled water. The $\mathrm{pH}$ was adjusted as mentioned in HTMC medium. The medium was filtered as mentioned above and added aseptically to the cultures of S. flexneri. Then, culturing was performed at $37{ }^{\circ} \mathrm{C}$ temperature, $\mathrm{pH}$ 7.0 and $17 \times g$ of agitation. Later, deoxycholate detergent at $0.5-1.0 \% \mathrm{w} / \mathrm{v}$ was added to the culture broth after attaining an optical density $\left(\mathrm{OD}_{600}\right)$ of 1.5 to extract the PS from the cell wall of $S$. flexneri [7].

\section{Synthetic Medium}

Seed cultures of Shigella flexneri were developed by sub-culturing into $300 \mathrm{ml}$ of synthetic medium and incubated in a rotary shaker at $37^{\circ} \mathrm{C}, 17 \times g$ of agitation for $12 \mathrm{~h}$. The composition of the medium included $178 \mathrm{~g}$ of $\mathrm{KH}_{2} \mathrm{PO}_{4}, 5.3 \mathrm{~g}$ of $\left(\mathrm{NH}_{4}\right)_{2} \mathrm{HPO}_{4}, 2.2 \mathrm{~g}$ of $\mathrm{C}_{6} \mathrm{H}_{8} \mathrm{O}_{7} \cdot \mathrm{H}_{2} \mathrm{O}, 1.5 \mathrm{~g}$ of $\mathrm{MgSO}_{4} \cdot 7 \mathrm{H}_{2} \mathrm{O}$, $30 \mathrm{ml}$ glycerol, $8.8 \mathrm{mg} \mathrm{C}_{12} \mathrm{H}_{17} \mathrm{~N}_{4} \mathrm{OS}$ and trace elements in a final volume of 11 distilled water. The $\mathrm{pH}$ was adjusted as mentioned above for the other two media. The medium was filtered as mentioned above and added aseptically to the cultures of S. flexneri. Then culturing was performed at $37^{\circ} \mathrm{C}$ temperature, $\mathrm{pH} 7.0$ and $26 \times g$ of agitation. Deoxycholate detergent at $0.5-1.0 \% \mathrm{w} / \mathrm{v}$ was added to the culture broth after attaining an optical density $\left(\mathrm{OD}_{600}\right)$ of 2.5 to extract the PS from the cell wall of S. flexneri [8]. 


\section{Hestrin Assay for PS Detection}

Acetylcholine standards were prepared (ranging from $12.5-200 \mu \mathrm{mol} / \mathrm{ml}$ whose final volume was made upto $1 \mathrm{ml}$ with distilled water) and then $400 \mu \mathrm{l}$ of hydroxyl amine hydroxide of 0.2-2 M was added to the harvested S. flexneri samples taken in independent flasks and incubation was done at different time intervals with the addition of $\mathrm{HCl}$ and $\mathrm{FeCl}_{3}$ of $0.1-0.4 \mathrm{M}$ to observe the brick red color formation. The absorbance was measured at $540 \mathrm{~nm}$ [6] to detect the presence of PS. The protein content in samples was estimated by the BCA spectrophotometric method (using Micro BCA protein assay kit from Thermo Fischer).

\section{Polysaccharide Purification Methods}

The PS from the crude extract of S. flexneri were separated from the impurities such as proteins and nucleic acids based on size, charge, hydrophilicity, affinity and solubility through different techniques to find the most optimized method for highest and purest yield. Scheme 1 depicts the various strategies employed in the purification of the extracted polysaccharide.

\section{Molecular Weight Cut Off Studies}

Molecular weight cut off studies is a basic parameter to estimate the approximate size of the bacterial PS. The crude culture S. flexneri was lysed by orthophosphoric acid of $0.5 \%$ $\mathrm{w} / \mathrm{v}$ and incubated for $3 \mathrm{~h}$ at $25{ }^{\circ} \mathrm{C}$. The $300 \mathrm{ml}$ of culture was centrifuged at $11,000 \times g$ at $4{ }^{\circ} \mathrm{C}$ for $30 \mathrm{~min}$ and the supernatant was collected. Selection of molecular weight cut off (MWCO) membrane amicon filters of 30, 50, 100, $500 \mathrm{kDa}$ from Merck, Millipore were used to estimate the molecular size of the PS from $S$. flexneri which was spun at $3800 \times g$ for $40-50 \mathrm{~min}$ to collect the supernatant [9].

\section{Phenol Chloroform Extraction}

Further, $600 \mathrm{ml}$ of the crude culture of $S$. flexneri was treated with phenol-chloroform in 3:1 ratio for purification of the PS. Cell suspension was supplemented with $50 \mathrm{mM}$ of EDTA. After 5 min of incubation under similar conditions, EDTA effect was stopped by adding approximately double the concentration of $\mathrm{MgCl}_{2}(100 \mathrm{mM})$. At this stage cells were re-centrifuged to obtain crude PS. The supernatant having bacterial cells with PS on their surface was subjected to Cetyl Trimethyl Ammonium Bromide (CTAB) precipitation of $5 \% \mathrm{v} / \mathrm{v}$ and centrifugation was done at $11,000 \times \mathrm{g}$ for $45 \mathrm{~min}$. This was followed by precipitation of PS for $3 \mathrm{~h}$ at $-20{ }^{\circ} \mathrm{C}$ using cold $\left(-20^{\circ} \mathrm{C}\right)$ absolute ethanol with $0.5 \mathrm{M}$ sodium chloride and $3 \mathrm{M}$ sodium acetate ( $\mathrm{pH}$ 5.2). Precipitated PS was collected using centrifugation and further suspended in small volume of $1 \mathrm{X}$ PBS ( $\mathrm{pH}$ 7.4) buffer. This method is limited due to consumption of time and usage of hazardous chemical like phenol $[10,11]$.

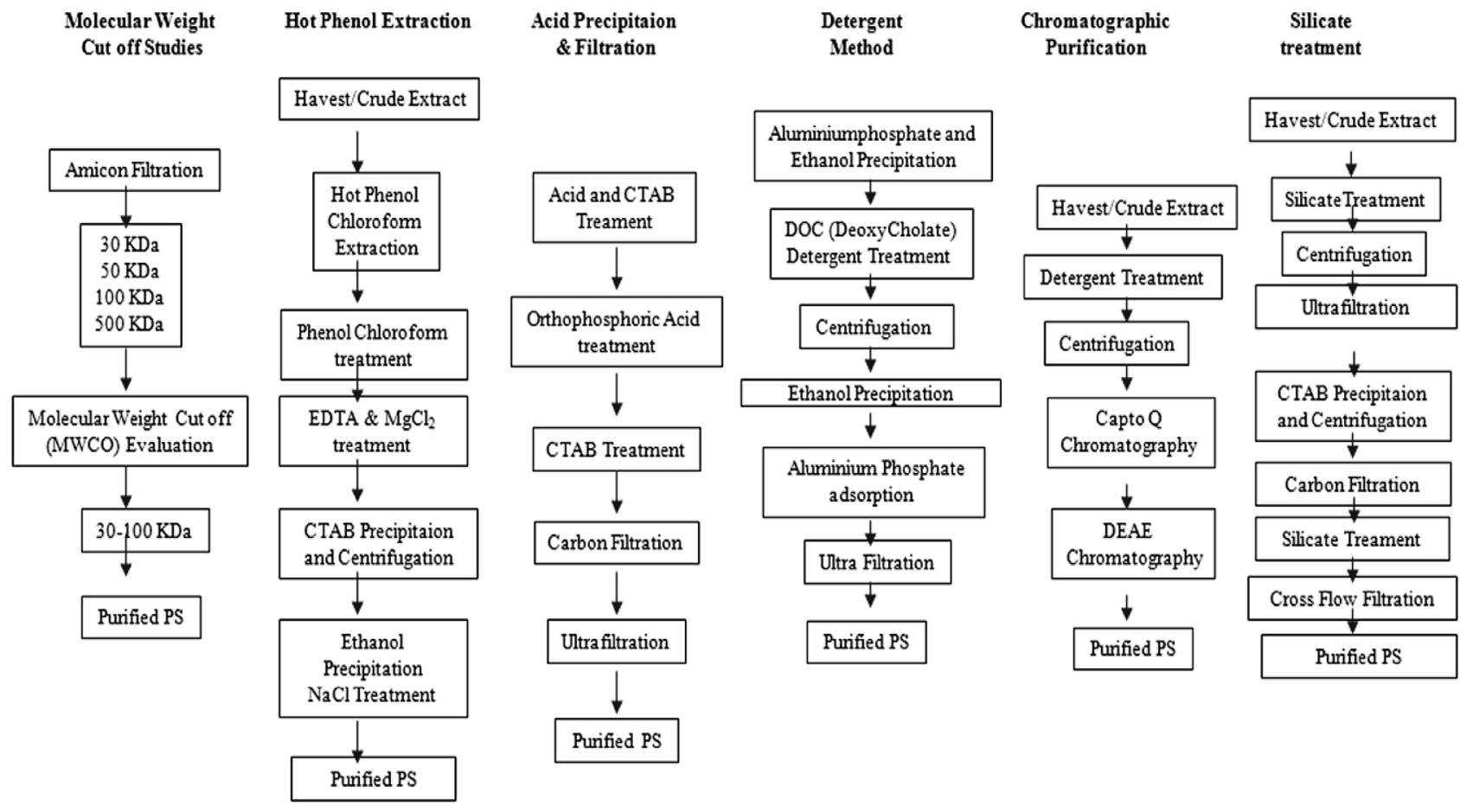

Scheme 1 Depicts the various polysaccharide purification strategies employed 


\section{Acid Precipitation and Filtration}

In this method, $600 \mathrm{ml}$ of the crude culture $S$. flexneri was lysed by $0.5 \% \mathrm{w} / \mathrm{v}$ of orthophosphoric acid and incubated for $3 \mathrm{~h}$ at $25^{\circ} \mathrm{C}$. The culture was centrifuged at $11,000 \times g$ at $4{ }^{\circ} \mathrm{C}$ for $30 \mathrm{~min}$. The supernatant was concentrated to 10-12 fold using $0.5 \mathrm{~m}^{2} 100 \mathrm{kDa}$ followed by CTAB precipitation $(5 \% \mathrm{v} / \mathrm{v})$ and centrifugation. It was collected after centrifugation and dissolved in $\sim 1000 \mathrm{ml}$ of distilled water followed by carbon filtration and further concentrated using a $30 \mathrm{kDa}$ tangential flow ultrafiltration (TFF) cut-off membrane, followed by filtration using $0.2 \mu \mathrm{m}$ membrane filter. The purified PS was stored at $-25{ }^{\circ} \mathrm{C}$. The disadvantage of this method is its lower extraction rate and difficulty in purifying the PS of our interest $[12,13]$.

\section{Detergent Method}

In this method, $600 \mathrm{ml}$ of the crude culture of $S$. flexneri was lysed by $0.2 \% \mathrm{w} / \mathrm{v}$ of sodium deoxycholate and incubated for $6 \mathrm{~h}$ at $35^{\circ} \mathrm{C}$. Then, the culture centrifuged at $11,000 \times g$ at $4{ }^{\circ} \mathrm{C}$ for $45 \mathrm{~min}$. The supernatant was concentrated to 5-10fold using $0.5 \mathrm{~m}^{2}$ of $100 \mathrm{kDa}$ membrane followed by $30 \% \mathrm{v} / \mathrm{v}$ of ethanol precipitation and then $6 \% \mathrm{w} / \mathrm{v}$ of $\mathrm{AlPO}_{4}$ addition. Further, the precipitated supernatant was incubated for $8 \mathrm{~h}$ at $25^{\circ} \mathrm{C}$ followed by centrifugation. The supernatant collected after centrifugation was once again concentrated and diafiltered using a $30 \mathrm{kDa}$ tangential flow ultrafiltration cut-off membrane followed by filtration using $0.2 \mu \mathrm{m}$ membrane filter. The purified PS was stored at $-25^{\circ} \mathrm{C}$. This method is not often suggestible for bacterial PS purification, due to the usage of ethanol step at high-scale operations [14, 15].

\section{Chromatographic Purification}

For chromatographic separation, $600 \mathrm{ml}$ of the crude culture of $S$. flexneri was lysed by $0.2 \%$ w/v sodium deoxycholate and incubated for $6 \mathrm{~h}$ at $35{ }^{\circ} \mathrm{C}$. Then, the culture centrifuged at $11,000 \times g$ at $4{ }^{\circ} \mathrm{C}$ for $45 \mathrm{~min}$. The supernatant obtained was concentrated to 5-10-fold using $0.5 \mathrm{~m}^{2}$ of $100 \mathrm{kDa}$ membrane followed by CTAB precipitation of $5 \% \mathrm{v} / \mathrm{v}$ and then centrifuged at $11,000 \times g$ for $45 \mathrm{~min}$. Then, the supernatant was passed through $0.45 \mu \mathrm{m}$ membrane filter for filtration. The ion exchange chromatography technique is further applied to purify the PS from S. flexneri permeate from the proteins and nucleic acids. Resins namely Capto $\mathrm{Q}$ and DEAE cellulose were used to pack the column with dimensions of $1.5 \times 25 \mathrm{~cm} .50 \mathrm{ml}$ solution (the permeate) was loaded in ion exchange column carefully and the separated fractions were collected at a flow rate of $30 \mathrm{ml} / \mathrm{h}$. Then $0.05 \mathrm{M}$ phosphate buffer ( $\mathrm{pH} 7.5$ ) was used for both the wash and equilibration. Each fraction is individually estimated for the presence of PS, proteins and nucleic acids [16, 17].

\section{Silicate Method}

In this novel method of separation, $600 \mathrm{ml}$ of the crude culture of $S$. flexneri was lysed by detergent sodium deoxycholate of $0.2 \% \mathrm{w} / \mathrm{v}$ and incubated for $6 \mathrm{~h}$ at $35^{\circ} \mathrm{C}$. Then, the culture centrifuged at $11,000 \times g$ at $4{ }^{\circ} \mathrm{C}$ for $45 \mathrm{~min}$. The supernatant was concentrated to $5-10$-fold using $0.5 \mathrm{~m}^{2}$ of $100 \mathrm{kDa}$ membrane followed by CTAB $(5 \% \mathrm{v} / \mathrm{v})$ precipitation and centrifugation at $11,000 \times g$ for $45 \mathrm{~min}$. The supernatant was then collected and passed through charcoal filters and further treated with $20 \mathrm{gm} / \mathrm{l}$ of silicate at room temperature with continuous stirring for $1 \mathrm{~h}$ followed by centrifugation. Then, the filtration with $0.45 \mu \mathrm{m}$ membrane filter was done followed by concentration and diafiltration using a $30 \mathrm{kDa}$ tangential flow ultrafiltration cut-off membrane followed by filtration using $0.2 \mu \mathrm{m}$ filter.

\section{Analytical Procedures}

Protein content for all processed samples was then determined utilizing the PS samples from $S$. flexneri cultures in independent synthetic media flask of $100 \mu$ by the spectrophotometric method using Bovine serum albumin as standard [18] and DNA content by absorption at $260 \mathrm{~nm}$ by spectrophotometric method [2] to assess the purity of the extracted PS. Statistical analysis for all the purifications and analytical methods were done by one-way ANOVA, using BIOSTAT software and the experimental values are mean of 20 replicates.

\section{High-Performance Liquid Chromatography}

Polysaccharide molecular weight distribution analysis was done using HPLC - size exclusion chromatography. Acidcleaved PS samples $S$. flexneri from independent synthetic media flask of $100 \mu \mathrm{l}$ were run on a TSK gel G3000 PWXL column $(30 \mathrm{~cm} \times 7.8 \mathrm{~mm}$; particle size $7 \mu \mathrm{m}$; cat.\# 808,021) with a TSK gel PWXL guard column $(4.0 \mathrm{~cm} \times 6.0 \mathrm{~mm}$; particle size $12 \mu \mathrm{m}$; cat.\# 808,033) (Tosoh Bioscience). The mobile phase consisted of $0.1 \mathrm{M} \mathrm{NaCl}, 0.1 \mathrm{M} \mathrm{NaH}_{2} \mathrm{PO}_{4}, 5 \%$ $\mathrm{CH}_{3} \mathrm{CN}$ at $\mathrm{pH} 7.2$ and a flow rate of $0.5 \mathrm{ml} / \mathrm{min}$ (isocratic method) for $30 \mathrm{~min}$. Void and bed volumes were calibrated with $\lambda$-DNA ( $\lambda$-DNA molecular weight marker III ranging from 0.12 to $21.2 \mathrm{Kbp}$ ) and sodium azide, respectively. The column void volume $\left(T_{0}\right)$ being $10.58 \mathrm{~min}$ and the total volume $\left(T_{\text {tot }}\right)$ being $23.03 \mathrm{~min}$ [19].

\section{HPAEC-PAD}

The sugar composition of the S. flexneri PS was determined by HPAEC-PAD using a Carbo Pac PA1 column $(50 \mathrm{~mm} \times 250 \mathrm{~mm})$ coupled to a CarboPac PA1 guard column and connected to Dionex KS5000 system. Samples 
diluted at $10 \mu \mathrm{g} / \mathrm{ml}$ of saccharide were treated with $\mathrm{NaOH}$ at a final concentration of $2 \mathrm{M}$, heated at $110{ }^{\circ} \mathrm{C}$ for $6 \mathrm{~h}$ in a closed screwcap test tube and filtered with $0.45 \mu \mathrm{m}$ filter before the analysis. The separation was performed with a flow rate of $1 \mathrm{ml} / \mathrm{min}$ using gradient elution of $100 \mathrm{mM}$ $\mathrm{NaOH}$ for 32 min with increased concentration of $\mathrm{NaNO}_{3}$ ranging from 8 to $50 \%$, followed by a washing step for $22 \mathrm{~min}$. The chromatography was monitored using the pulsed amperometric mode with a gold working electrode and an $\mathrm{Ag} / \mathrm{AgCl}$ reference electrode. A quadruple-potential waveform for carbohydrates was used. The chromatographic data were processed using Dionex Chromeleon TM software. The calibration curve was set up with glucose (Fluka) in the range of $1.0-25.0 \mu \mathrm{g} / \mathrm{ml}$ which was treated the same way as the samples mentioned above [20]. All the above experiments have been performed in triplicates and the results are the mean of those three readings.

\section{Results}

\section{Production of PS}

It is important to reduce the cost of PS production and purification and to attain the maximum quantity from the $S$. flexneri culture. Therefore, in the current study, three important nutritive media namely HTMC, SSDM and Synthetic media were utilized to culture the experimental batches of S. flexneri. From the bacterial growth curve, it was observed that flask culture with synthetic media promoted maximum $S$. flexneri growth rate in a short period of time i.e., within 12 h [Fig. 1]. But, significant $S$. flexneri growth was observed only after $24 \mathrm{~h}$ from the HTMC and SSDM media.

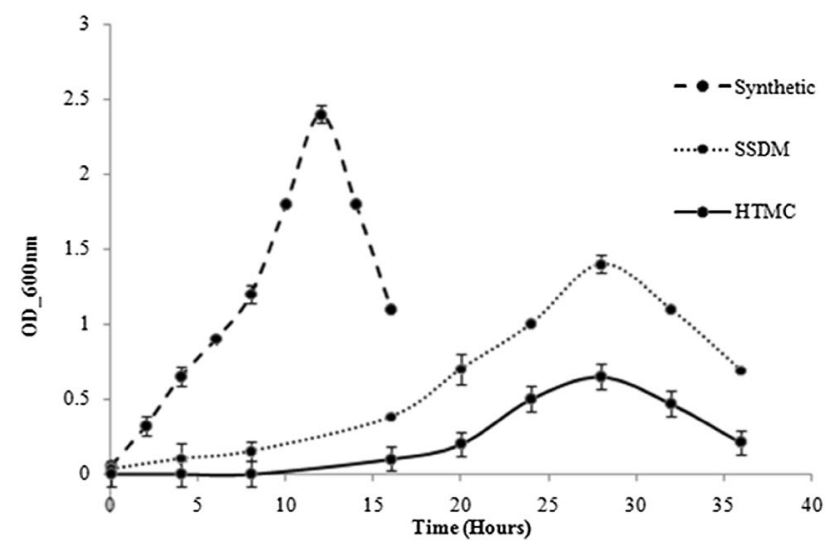

Fig. 1 Mean data of growth index measurement of $S$. flexneri under three growth media conditions. Values are mean of 20 replicates \pm SE; Statistical analysis by one-way ANOVA showed that there was a significant difference at $P<0.05$ level between the different samples
Hestrin assay was performed to detect the quantity of PS produced from the cultures of $S$. flexneri that were harvested utilizing the three different media namely HTMC, SSDM and Synthetic media. From Table 1, it was evident that the produced PS of $1.26 \mathrm{mg} / \mathrm{ml}$ content was higher in the culture samples of $S$. flexneri grown using the Synthetic media. The yields of PS from S. flexneri grown on Synthetic medium based on the optical density (OD) at $600 \mathrm{~nm}\left(\mathrm{OD}_{600}-2.4\right)$ was significantly higher than that grown on $\operatorname{HTMC}\left(\mathrm{OD}_{600}-0.65\right)$ and $\operatorname{SSDM}\left(\mathrm{OD}_{600^{-1.4}}\right)$ media.

\section{Purification of PS}

PS present on the surface of the $S$. flexneri acts as a barrier for the foreign particles and carries the antigenicity. In order to extract this PS from this pathogenic bacteria, various traditional purification methods were employed namely molecular weight cut off studies, phenol-chloroform extraction, acid precipitation and detergent method. From Table 2 representing the contribution of each purification step, it is evident that the quantity of PS extracted from $S$. flexneri varied significantly from each purification process. Evaluation of PS from S. flexneri through molecular weight cut off studies, denoted its molecular weight to be well within the standard range of 150 to $500 \mathrm{KDa}$, important for conjugation studies. Insignificant quantities of PS from $S$. flexneri were extracted from the phenol chloroform extraction process with $0.1-0.2 \mathrm{mg} / \mathrm{ml}$ of yield. Whereas, moderate levels of PS of $0.2-0.4 \mathrm{mg} / \mathrm{ml}$ were extracted from S. flexneri through the acid precipitation and detergent purification methods. Due to the insignificant yields from these traditional methods, chromatographic purification and a novel silicate method for the first time was devised and employed for the purification of the PS for enhanced yield. Further, in the study, it was observed that after removal of impurities such as proteins and nucleic acids, $0.8-1 \mathrm{mg} / \mathrm{l}$ of the bacterial PS was obtained by employing chromatographic purification method. But the purified PS product recovery from $S$. flexneri is $1-1.2 \mathrm{mg} / \mathrm{l}$ which is significantly higher in the silicate purification method compared to the other

Table 1 Estimation of PS content from S. flexneri cultured in three different media at $12 \mathrm{~h}$ by Hestrin assay

\begin{tabular}{llll}
\hline S. no & Media & $\begin{array}{l}\text { Absorbance at } 540 \mathrm{~nm} \\
\text { Avg OD } \pm \text { SD (of 20 replicates) }\end{array}$ & $\begin{array}{l}\text { PS con- } \\
\text { tent (mg/ } \\
\text { ml) }\end{array}$ \\
\hline 1 & HTMC & $0.028 \pm 0.005$ & 0.608 \\
2 & SSDM & $0.029 \pm 0.006$ & 0.702 \\
3 & Synthetic & $0.036 \pm 0.006$ & 1.260 \\
\hline
\end{tabular}

All parameters were expressed in $\mathrm{mg} / \mathrm{ml}$ and values are mean $\pm \mathrm{SD}$ $(n=20)$. Values followed by different letters in a column are statistically different at $P<0.05$ [4] 
Table 2 Stepwise purification of PS content from S. flexneri culture employing various purification techniques

\begin{tabular}{|c|c|c|c|}
\hline & Proteins (mg/ml) & Nucleic acids & Polysaccharide $(\mathrm{mg} / \mathrm{ml})$ \\
\hline \multicolumn{4}{|c|}{ Molecular weight cut-off studies } \\
\hline $30 \mathrm{KDa}$ & $0.85 \pm 0.0002$ & $0.55 \pm 0.0004$ & $0.72 \pm 0.0006$ \\
\hline $50 \mathrm{KDa}$ & $0.81 \pm 0.0004$ & $0.46 \pm 0.0002$ & $0.68 \pm 0.0006$ \\
\hline $100 \mathrm{KDa}$ & $0.67 \pm 0.0006$ & $0.39 \pm 0.0002$ & $0.65 \pm 0.003$ \\
\hline $500 \mathrm{KDa}$ & $0.55 \pm 0.0004$ & $0.35 \pm 0.0002$ & $0.39 \pm 0.001$ \\
\hline \multicolumn{4}{|c|}{ Phenol-chloroform extraction } \\
\hline Phenol-chloroform & $2.7 \pm 0.0007$ & $1.8 \pm 0.0006$ & $0.2 \pm 0.0013$ \\
\hline EDTA & $2.1 \pm 0.0006$ & $1.7 \pm 0.0009$ & $0.1 \pm 0.0023$ \\
\hline Filtration & $1.8 \pm 0.0012$ & $1.6 \pm 0.0012$ & $0.05 \pm 0.0004$ \\
\hline \multicolumn{4}{|c|}{ Acid precipitation and filtration } \\
\hline Acid lysis & $2.3 \pm 0.0133$ & $1.8 \pm 0.001$ & $0.7 \pm 0.004$ \\
\hline CTAB precipitation & $1.8 \pm 0.001$ & $1.6 \pm 0.023$ & $0.45 \pm 0.001$ \\
\hline Characoal & $1.4 \pm 0.001$ & $1.4 \pm 0.001$ & $0.39 \pm 0.004$ \\
\hline Diafiltration & $1.3 \pm 0.023$ & $1.4 \pm 0.001$ & $0.2 \pm 0.023$ \\
\hline Microfiltration & $1.1 \pm 0.043$ & $1.2 \pm 0.023$ & $0.13 \pm 0.003$ \\
\hline \multicolumn{4}{|l|}{ Detergent method } \\
\hline Detergent lysis & $1.75 \pm 0.0009$ & $3.2 \pm 0.0043$ & $2.2 \pm 0.0023$ \\
\hline Ethanol precipitation & $1.59 \pm 0.0002$ & $2.7 \pm 0.004$ & $0.8 \pm 0.001$ \\
\hline $\mathrm{AlPO}_{3}$ adsorption & $1.4 \pm 0.0433$ & $2.3 \pm 0.004$ & $0.6 \pm 0.0023$ \\
\hline Diafiltration & $1.3 \pm 0.004$ & $1.8 \pm 0.003$ & $0.4 \pm 0.0023$ \\
\hline Microfiltration & $1.2 \pm 0.003$ & $1.5 \pm 0.006$ & $0.25 \pm 0.0043$ \\
\hline \multicolumn{4}{|c|}{ Chromatographic purification } \\
\hline Detergent lysis & $1.9 \pm 0.093$ & $2.8 \pm 0.043$ & $2.5 \pm 0.04$ \\
\hline Ultrafiltration & $1.5 \pm 0.013$ & $2.4 \pm 0.063$ & $1.8 \pm 0.023$ \\
\hline CTAB treatment & $1.1 \pm 0.013$ & $1.8 \pm 0.023$ & $1.6 \pm 0.063$ \\
\hline Charcoal filtration & $0.8 \pm 0.023$ & $1.4 \pm 0.04$ & $1.4 \pm 0.013$ \\
\hline Silicate treatment & $0.19 \pm 0.001$ & $0.5 \pm 0.01$ & $0.95 \pm 0.006$ \\
\hline Ultrafiltration & $0.15 \pm 0.001$ & $0.75 \pm 0.03$ & $0.92 \pm 0.003$ \\
\hline Microfiltration & $0.10 \pm 0.063$ & $0.1 \pm 0.03$ & $0.85 \pm 0.001$ \\
\hline \multicolumn{4}{|l|}{ Silicate method } \\
\hline Detergent lysis & $1.9 \pm 0.001$ & $2.8 \pm 0.001$ & $2.5 \pm 0.043$ \\
\hline Ultrafiltration & $1.5 \pm 0.002$ & $2.4 \pm 0.001$ & $1.8 \pm 0.001$ \\
\hline CTAB treatment & $1.1 \pm 0.003$ & $1.8 \pm 0.001$ & $1.6 \pm 0.001$ \\
\hline Charcoal filtration & $0.8 \pm 0.001$ & $1.2 \pm 0.001$ & $1.4 \pm 0.002$ \\
\hline Silicate treatment & $0.19 \pm 0.033$ & $0.14 \pm 0.004$ & $1.1 \pm 0.001$ \\
\hline Ultrafiltration & $0.15 \pm 0.002$ & $0.13 \pm 0.003$ & $0.95 \pm 0.004$ \\
\hline Microfiltration & $0.10 \pm 0.003$ & $0.10 \pm 0.003$ & $0.92 \pm 0.001$ \\
\hline
\end{tabular}

Values are mean of 20 replicates \pm SE. Statistical analysis by one-way ANOVA showed that there was a significant difference at $P<0.05$ level between the different samples purification methods employed. This proved the efficacy of the newly devised silicate method.

Analysis of the molecular weight distribution of the obtained purified PS from $S$. flexneri was performed using HPLC. Figure 2 shows the molecular weight of purified PS from $S$. flexneri to be varying from 176, 192 and $199 \mathrm{KDa}$ for the three experimental batches of cultures which were well within the standard range of 150 to $300 \mathrm{KDa}$ required for conjugation studies. Later, the cell wall sugar composition of the PS from $S$. flexneri was studied using HPEAC-PAD chromatography. Figure 3 revealed the various identified sugars as $\mathrm{N}$-acetyl glucosamine, Rhamnose and Galactose in the PS isolated from S. flexneri when run against their standards.

\section{Discussion}

The growth profiles and the PS production from S. flexneri culture are important factors, as they determine the optimal harvest time and economy of downstream processes for the 
Fig. 2 HPLC chromatography profile of purified PS from three different batches of $S$. flexneri culture representing the average molecular weight distribution in KDa. The HPLC profile was detected by RI using HP-GPC column. The peak at $12.42 \mathrm{~min}$ represents the purified polysaccharide from different batches with molecular weights of 199 , 192 and $176 \mathrm{KDa}$
Fig. 3 Representation of various sugar moieties in the PS isolated from $S$. flexneri through HPAEC-PAD chromatogram. Peak 1 corresponds to $N$-acetyl glucosamine with retention time of $7.3 \mathrm{~min}$, Peak 2 corresponds to Rhamnose with the retention time of 8.5 min and Peak 3 represents to Glucose with the retention time of $11.4 \mathrm{~min}$
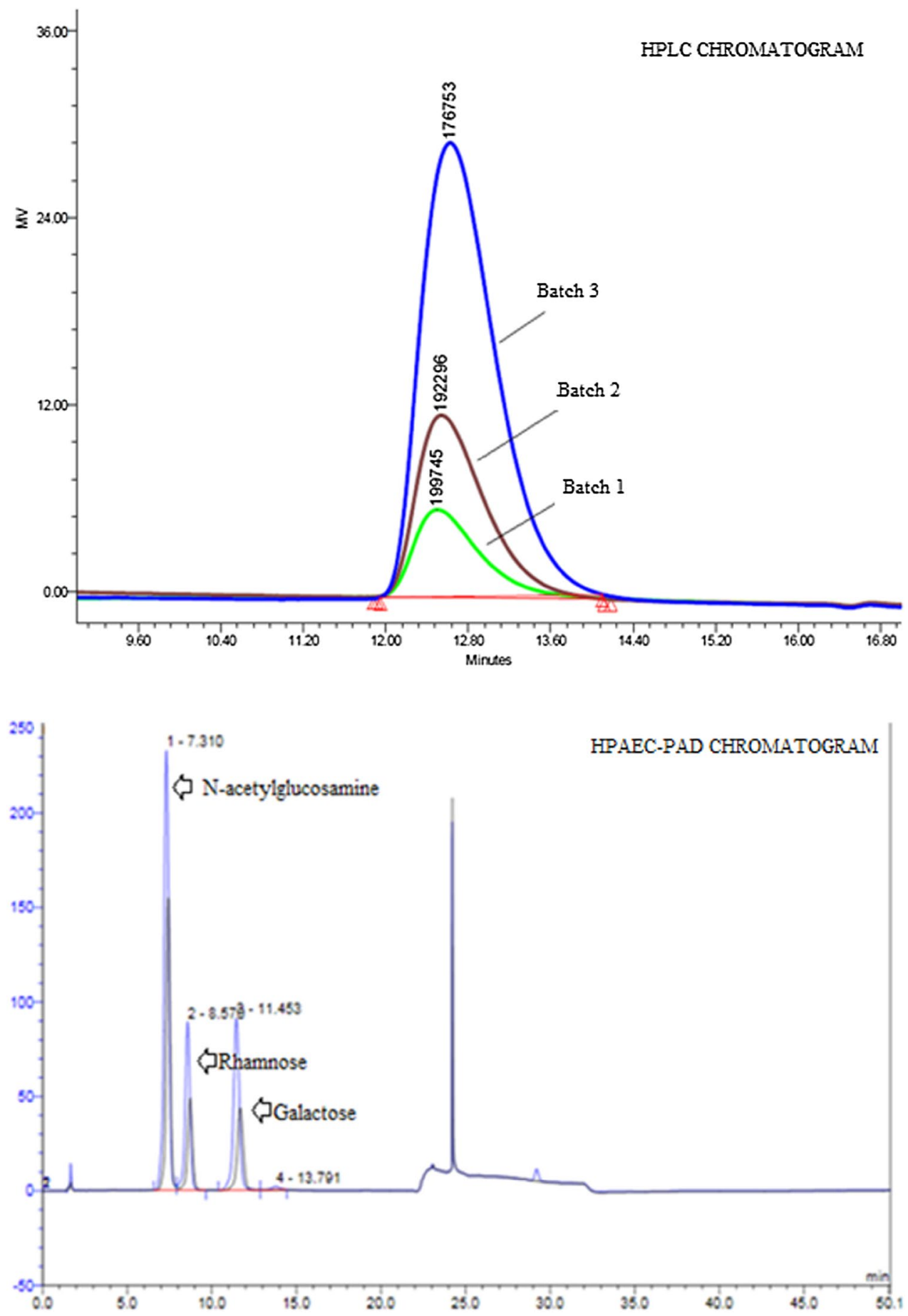

conjugate vaccines. During the culture of $S$. flexneri, the fermentation media, physical-chemical parameters and feeding strategy are the prime most factors for the bacterial growth. An improved bacterial growth will correspond to higher yields of PS [21, 22]. In the present study, it is observed that the synthetic media enhanced the growth of the $S$. flexneri in reduced time period of within $12 \mathrm{~h}$ compared to HTMC and SSDM media. It is also known that the presence of glucose, amino acids and minerals are usually essential and enhance the bacterial growth [23]. The synthetic media utilized for the culture of $S$. flexneri constituted glucose as one of its main constituents. Thus, the glucose content (a major carbon source) in the synthetic media might have enhanced the $S$. flexneri growth rates in comparison to the HTMC and SSDM media. This indicates that the PS production corresponds to the bacterial growth rates depending on the composition of the growth media [23, 24]. 
A purified and an economical production of PS from $S$. flexneri is very important towards the synthesis of PS-based conjugate vaccines. Hence, the aim of the present study was to develop an efficient purification method for the extraction of PS from the pathogenic S. flexneri bacteria that provides both higher yield and purity. PS production using conventional methods such as phenol-chloroform extraction and acid precipitation resulted in large impurities of proteins and nucleic acids [25]. From the literature, it is also evident that the usage of acid in these purification methods had reported a degradative effect on the extracted PS [26]. The detergent method employed in the present study is a traditional bacterial PS extraction method and often associated with the ethanol precipitation for better yields of purified PS [1]. Further, in order to eliminate the usage of organic solutions, the chromatographic purification method was adopted for the extraction of PS from S. flexneri [27]. In this study, the chromatography method is further improved with the step-up of tangential flow filtration approach for the purification of bacterial PS samples. This tangential flow filtration purification step is very efficient and the membranes were easy to clean and can be reused several times [28, 29]. Further, in the present study, an efficient silicate method was developed for the purification of PS from S. flexneri that greatly reduces time by eliminating the effect of phenol, solvents and chromatography resin process steps. This newly devised silicate method employed uses the advantage of the silica powder and charcoal treatments, and removes the impurities very efficiently. Silicate adsorbs nucleic acid and protein impurities very efficiently. The silicate method is cheaper than chromatographic columns for large-scale operations. Handling silica during polysaccharide recovery is less time consuming. This alternative silicate purification process significantly recovered high yields of purified PS from the pathogenic S. flexneri bacteria. In addition, this method is proved to be scalable and economical for the large-scale manufacturing of $S$. flexneri PS-conjugated vaccines. The average molecular distribution of the purified polysaccharide was further confirmed by HPLC to be well within the standard range of 150-300 KDa, which is optimal for conjugation studies. The sugar composition of the PS was confirmed to be N-acetyl glucosamine, rhamnose, and galactose by HPAEC-PAD based study on the retention time in comparison to their standards.

\section{Conclusion}

The present study was a successful attempt towards a cost-effective way of high-rate production of PS from the cell wall of $S$. flexneri through a newly devised technique called silicate method used for the first time in this study.
The experimental findings of the current study have shown that the synthetic media have the potential to enhance the yield of PS of $S$. flexneri to 2 folds $(1.26 \mathrm{mg} / \mathrm{ml})$ within a short time of $12 \mathrm{~h}$ when compared to $0.608 \mathrm{mg} / \mathrm{ml}$ in HTMC and $0.702 \mathrm{mg} / \mathrm{ml}$ in SSDM media. It was also shown that the utilization of the synthetic media is reproducible and produces debris free products that ease the process of PS purification from $S$. flexneri. In addition, the present study also provided an improved silicate method for PS extraction with enhanced yield of 20-35\% (compared to traditional approaches employed in the current study) and purity which can be speculated to be applied to other Gram-negative pathogens as well. This novel silicate method employed in this study for the first time could be potentially used for the development of PS-based conjugate vaccines in industrial scale-up production. Overall, the developed method is relatively more efficient (with enhanced yield), clean (healthy extraction with reduced impurities) and cost-effective for pilot scale production.

Acknowledgement Authors are grateful to Biological E. Limited, AIC facility, Hyderabad, India and Department of Biological Sciences, BITS Pilani, Hyderabad Campus for the infrastructure and facilities for the present work.

\section{Compliance with Ethical Standards}

Conflict of interest This paper has not been published before in any form and it is not under consideration by any other journal at the same time. All the authors approve the manuscript submission to this journal and none of the authors have any conflicting interests in the manuscript.

\section{References}

1. Lambent LM, Bourgeois AL, Fischer-Walker CL, Black RE, Sack D (2014) Estimating diarrheal illness and deaths attributable to Shigellae and enterotoxigenic Escherichia coli among older children, adolescents, and adults in South Asia and Africa. PLoS Negl Trop Dis 8(2):e2705

2. Guidelines for the control of epidemics due to Shigella dysenteriae type 1. WHO/CDR/95.4.2006. Recommendations to assure the quality, safety and efficacy of group A Meningococcal conjugate vaccines. WHO/BS/06.2041.

3. Kotloff KL, Winickoff JP, Ivanoff B, Clemens JD, Swerdlow DL, Sansonetti PJ, Adak GK, Levine MM (1999) Global burden of Shigella infections: implications for vaccine development and implementation of control strategies. WHO 77(8):651-666

4. Changfa C, Carbis R, Jung S, An SJ, Jang H, Czerkinsky C, Szu S, Clemens JD (2010) Physical and chemical characterization and immunologic properties of salmonella enteric serovar Typhi capsular polysaccharide-diphtheria toxoid conjugates. Am Soc Microbiol 17(1):73-79

5. Hu Q-Y, Allan M, Adamo R, Quinn D, Zhai H, Wu G, Clark K, Zhou J, Ortiz S, Wang B, Danieli E, Crotti S, Tontini M, Brogioni G, Berti F (2013) Synthesis of a well-defined glycoconjugate vaccine by a tyrosine-selective conjugation strategy. Chem Sci $4: 3827-3832$ 
6. Kämpf MM, Braun M, Sirena D, Ihssen J, Thony-Meyer L, Ren $Q$ (2015) In vivo production of a novel glycoconjugate vaccine against Shigella flexneri 2a in recombinant Escherichia coli: identification of stimulating factors for in vivo glycosylation. Microb Cell Fact 14:12

7. Berlanda SF, Colucci AM, Maggiore L, Sanzone S, Rossi O, Ferlengh I, Pesce I, Caboni M, Norais N, Di Cioccio V, Saul A, Gerke C (2012) High yield production process for Shigella outer membrane particles. PLoS ONE 7(6):e0134478

8. Micoli F, Rondini S, Gavini M, Lanzilao L, Medaglini D (2012) O:2-CRM197 conjugates against Salmonella Paratyphi A. PLoS ONE 7(11):1-14

9. Ziadi M, Bouzaiene T, M'Hir S, Zaafouri K, Mokhtar F, Hamdi M, Boisset-Helbert C (2018) Evaluation of the efficiency of ethanol precipitation and ultrafiltration on the purification and characteristics of exopolysaccharides produced by three lactic acid bacteria. BioMed Res Int. https://doi.org/10.1155/2018/1896240

10. Nadim A, Katti DS (2016) A two-step method for extraction of lipopolysaccharide from Shigella dysenteriae serotype 1 and Salmonella typhimurium: an improved method for enhanced yield and purity. J Microbiol Methods 127:41-50

11. Abu-Baker NF, Masoud H (2016) Synthesis, characterization, and immunological properties of LPS-based vaccines composed of O-polysaccharides conjugated with recombinant exoprotein A from Pseudomonas aeruginosa. Adv Microbiol 6(4):332-342

12. Norma S, Laura F, Fraguas Esther T, Massaldi H, Batista-Viera F, Ferreira F (2001) Production of capsular polysaccharide of Streptococcus pneumoniae type 14. Appl Environ Microbiol 67(2):969-971

13. Rezania S, Amirmozoaffari N, Tabarraei B, Jeddi-Tehrani M, Zarei O, Alizadeh R, Masjedian F, Zarnani AH (2011) Extraction, purification and characterization of lipopolysaccharide from Escherichia coli and Salmonella Typhi. Avicenna J Med Biotechnol 3(1):3-9

14. Boom R, Sol CJ, Salimans MM, Jansen CL, Wertheim-van Dillen PM, Noordaa V (1990) Rapid and simple method for purification of nucleic acids. J Clin Microbiol 28(3):495-503

15. Takagi M, Lima RB, Albani SM, Zangirolami TC, Tanizaki MM, Cabrera-Crespo J (2008) Purification of capsular polysaccharide produced by Haemophilus influenzae type b through a simple, efficient and suitable method for scale-up. J Ind Microbiol 35(11):1217-1222

16. Al-Agha AGM (2017) Extraction and purification of lipopolysaccharide of Klebsiella pneumoniae isolates. Int J Curr Microbiol Appl Sci 6(8):90-100

17. Gu F, Chodavarapu K, McCreary D, Plitt TA, Tamoria E, Ni M, Burnham JJ, Peters M, Lenhoff AM (2015) Silica-based strong anion exchange media for protein purification. J Chromatogr A 13(76):53-63

18. Lowry OH, Rosebrough NJ, Farr AL, Randall RJ (1951) Protein measurement with the Folin phenol reagent. J Biol Chem 193:265-275
19. Fang G, Swann C, Rigsby P, Lockyer K, Logan A, Rijpkema S, Bolgiano B, Vi IS Working Group (2017) Evaluation of candidate international standards for VI polysaccharide from Citrobacter freundii and Salmonella enterica subspecies enteric serovar Typhi. Expert committee on biological standardization. World Health Organization. https://apps.who.int/iris/handle/10665/260484

20. Ricci S, Bardotti A, D’Ascenzi S (2001) Development of a new method for the quantitative analysis of the extracellular polysaccharide of Neisseria meningitides serogroup A by use of highperformance anion-exchange chromatography with pulsed-amperometric detection. Vaccine 19:1989-1997

21. Henriques AWS, Jessouroun E, Lima EL, Alves TLM (2005) Mathematical modeling of capsular polysaccharide production by Neisseria meningitides serogroup C in bioreactors. Braz J Chem Eng 22(4):585-592

22. Zhan X, Zhu L, Wu J, Zhen Z, Jia W (2002) Production of polysialic acid from fed-batch fermentation with $\mathrm{pH}$ control. Biochem Eng J 11(2):201-204

23. Bueno SM, Garcia-Cruz CH (2006) Optimization of polysaccharides production by bacteria isolated from soil. Braz J Microbiol 37(3):296-301

24. Götz A, Goebel W (2010) Glucose and glucose-6-phosphate as carbon sources in extra- and intracellular growth of enteroinvasive Escherichia coli and Salmonella enterica. Microbiology 156:1176-1187

25. Muck A, Ramm M, Hamburger M (1999) Efficient method for preparation of highly purified lipopolysaccharides by hydrophobic interaction chromatography. J Chromatogr B Biomed Sci Appl 732(1):39-46

26. Yi EC, Hackett M (2000) Rapid isolation method for lipopolysaccharide and lipid A from Gram-negative bacteria. Analyst 125(4):651-656

27. Ji Y, Tian Y, Ahnfelt M, Sui L (2014) Design and optimization of a chromatographic purification process for Streptococcus pneumoniae serotype $23 \mathrm{~F}$ capsular polysaccharide by a design of experiments approach. J Chromatogr A 1348:137-149

28. Albani SM, da Silva MR, Takagi M, Cabrera-Crespo J (2012) Improvement in the purification process of the capsular polysaccharide from Haemophilus influenzae type b by using tangential ultrafiltration and diafiltration. Appl Biochem Biotechnol 167:2068-2075

29. Lise B, Fabre V, Fettig M, Gousseinov E, Kawakami Y, Laroudie N, Scanlan C, Pattnaik P (2016) Clarification of vaccines: an overview of filter based technology trends and best practices. Biotechnol Adv 34(1):1-13

Publisher's Note Springer Nature remains neutral with regard to jurisdictional claims in published maps and institutional affiliations. 